\title{
Performing the Nation: Pedagogical Embodiment as Civic Text
}

Kyle A. Greenwalt; Michigan State University

Email:greenwlt@msu.edu

Kevin J. Holohan; Michigan State University

Email: holohank@msu.edu

\section{Abstract}

This paper explores the ways in which narratives speak to issues of national identity - its production, reproduction, and contextual performance. Drawing first upon literature in history education, the paper explores the multivoiced nature of the historical narratives which structure American national identity projects. The paper next employs phenomenological methodology in order to explore the narratives produced by students in speaking about school experiences, which they found to have a national component. In this section, there is a particular focus on the teacher as a powerful text as read by students - a curriculum of its own right. The paper concludes by moving to theorize, using phenomenological and post-structural analyses, the relationship between the personal and the national, lived and historical experiences - while maintaining a focus on the civic and pedagogical implications of the data analysis.

\section{Introduction}

Connecting narratives of lived experience to identity is an important task for educational researchers interested in a transformational view of the United States of America (USA), schooling, society, and citizenship. Differing versions of the past - a past remembered both individually and collectively - suggest differing courses of action in the present. The desire and ability to participate in democratic living itself is a function of the identity which one narrates and has narrated for one's self: the tension between belonging and recognition which brings about, as Dewey (1916/1997) put it, “equable opportunity to receive and take from others” in the process of creating "a large variety of shared undertakings and experiences” (p. 84). Schooling has historically played an important role in these processes, as it provides young people with some of their first experiences in communal membership. In short, how young people experience schools impacts not only the stories they tell about themselves, but equally what the stories tell about the groups to which they belong.

This paper examines the ways in which narratives of schooling are performed and the civic opportunities, which these "identity resources" both deny and afford (Wertsch, 2002). It does this though analyses of students' lived experiences. In the process, we invite the reader to think about 
one issue in particular facing us as teachers, researchers, and citizens: the perennial question of what in school does the educating. That is, we seek to raise the question of the degree to which the focus on subject-matter standardization has resulted in powerful-classroom experiences; ones students draw upon in constructing their identities. We pose this question in light of the tendency to understand subject matter as distinct from its potential pedagogical enactments, by real fleshand-blood teachers, ones who are managing much more than subject-matter considerations at any one point in the moment. Indeed, one purpose of this paper is to examine these embodied moments of teaching as identity-forming texts from which young people draw in constructing their understandings of themselves.

In this paper, we will explore the ways in which narratives speak to issues of both personal and national identity - their production, reproduction, and contextual performance. Drawing first upon literature in history education, the paper explores the multivoiced nature of the historical narratives which structure American national identity projects. The paper next employs phenomenological methodology in order to explore the narratives produced by students in speaking about school experiences, which they found to have a national component. In this section, there is a particular focus on the teacher as a powerful text which is read by students - a curriculum in its own right. The paper concludes by moving to theorize, using phenomenological and post-structural analyses, the relationship between the personal and the national, lived and historical experiences - while maintaining a focus on the civic and pedagogical implications of the data analysis.

\section{National Narratives and National Identity: Personalizing Images of America}

Narratives of the past are one of the primary tools that are used to construct an identity in the present. This is true on both the personal and the social levels. As Barton and Levstik (1998) convincingly wrote:

the construction of the past is always a selective process, in which certain people, events, and trends are remembered, emphasized, and even celebrated while others are forgotten, excluded or deemphasized . . . those aspects of the past most likely to be considered significant are those that lead to identification with a particular social order and ratify a community's social and cultural practices. In this view, history has little to do with establishing what happened in the past but everything to do with the promotion of social unity and consensus in the present. (italics added for emphasis, p. 482)

To a large degree, we use the interrelatedness of narratives of the past and identity-forming texts in the present as the conceptual framework in this study.

Wertsch and O'Connor (1994) were perhaps the first researchers to identify a "quest for freedom" theme as dominating the narratives told about the USA - and the performative national identity that is its concomitant. ${ }^{1}$ Subsequent research done on this topic during the 1990 s and early 2000s tended to validate this finding, especially as it relates to white Americans (Barton \& Levstik, 1998; Cornbleth, 2002; Epstein, 2000; Mosborg, 2002 ${ }^{2}$ ). Indeed, such is the strength of this finding that Barton and Levstik (2004) could write that "two themes are at the core of the story Americans most often tell themselves and their children about the nation's past:” freedom and progress (p. 167). This is, of course, in spite of the fact that entire populations of the USA 
have been denied both personal and collective freedoms, and that any notion of progress must necessarily ignore the contingent, uneven, and uncertain nature of historical change.

In the work of Wertsch and O'Connor (1994), a “quest for freedom” theme dominated the American national identity constructed by the college students they studied. Participants were simply asked to "spend thirty minutes to an hour writing an essay describing the origins of the United States” (p. 300). The data analysis revealed that participants saw U.S. history as the unfolding of greater freedoms and the steady expansion of rights; that is, "participants appropriated one general item from a 'stock of stories' . . . and this item organized the text" (p. 301). On the other hand, the authors also noted the various textual tactics participants could use to challenge or resist such a view of American national identity. Such examples include a satiric retelling of the dominant narrative, or the insertion of authorial commentary into the narrative.

Drawing upon the work of Bakhtin (2000), Wertsch and O'Connor (1994) name these forms of accommodation and resistance to the dominant ways of narrating as "multivoicedness." Multivoicedness is a term that captures the fact that one's personal speech necessarily draws upon the words of others, thereby infusing one's own speech with both the intentions and contexts of others. That is, all speech has a history, and that history must in some way be confronted:

The word in language is half someone else's. It becomes “one’s own” only when the speaker populates it with his own intention, his own accent, when he appropriates the word, adapting it to his own semantic and expressive intention. Prior to the moment of appropriation, the word does not exist in a neutral and impersonal language . . . but rather it exists in other people's mouths, in other people's contexts, serving other people's intentions: it is from there that one must take the word, and make it one's own. (Bakhtin, 2000, pp. 293-294)

Hence, the somewhat uniform nature of the stories told about the United States and its citizens in the Wertsch and O'Connor study are to be expected - for participants were coming to terms with the authority of certain images of the US (their hegemony and social ubiquity) while at the same time working to appropriate those images for personal intentions (as either means of personal affiliation with, or resistance to, the authoritative forms of national identity).

\section{Foregrounding the School's Mediation between the National and the Personal}

Wertsch and O'Connor (1994) focused their analysis more on narrative representations and less on national identity. Hence, the multivoicedness they explore deals more with discursive strategies for representing the actions of others ("history") and less with those strategies participants might use for making sense of their own actions ("biography" or "life history"). ${ }^{3}$ Hence, we see a need for research that focuses more on the ways in which authoritative discourses about national identity ${ }^{4}$ are appropriated so as to make sense of one's own life.

There can be little doubt that the social context in which young people have grown up has shifted over the first decade of the twenty-first century - subsequent to the time during which this research (i.e., Barton \& Levstik, 1998; Cornbleth, 2002; Epstein, 2000; Mosborg, 2002; Wertsch \& O’Connor, 1994) was completed. Though valuations of historical change are always 
dependent upon the position of the subject making such judgments, declarations like the one recently published in Time magazine - if they do not capture - at least help to shape the collective American experience of the past decade:

Bookended by $9 / 11$ at the start and a financial wipeout at the end, the first 10 years of this century will very likely go down as the most dispiriting and disillusioning decade Americans have lived through in the post-World War II era. We're still weeks away from the end of '09, but it's not too early to pass judgment. Call it the Decade from Hell, or the Reckoning, or the Decade of Broken Dreams, or the Lost Decade. Call it whatever you want - just give thanks that it is nearly over. (Serwer, 2009, para. 1)

Hence, the authoritative discourse about America and American national identity has - it would seem - changed since the 1990s, and any such changes must be taken into consideration by researchers. Yet little research has revisited the topic of narrative, national identity, and the public schools.

We will set out to do this by building upon Bakhtin's notion of multivoicedness, suggesting in the process that studies of American national identity need to do a better job of foregrounding the personal - that is, the way in which authoritative discourses, images, and narratives are appropriated by individual speakers to understand their national identity. In this, we see our own research as extending that done in the past. Like Cornbleth (2002), we recognize the mediating function of schooling in the construction of national identity. In particular, the importance of teachers as mediators of national identity - as a type of curriculum in and of themselves - will emerge in the course of data presentation. In all aspects of the study, though, we remain particularly alert to the multivoiced interplay that is so characteristic of past research, and that is present in this study as well: the way in which the national and local, subject-matter and hidden curricula, lived and historical experience, come into conflict and play.

\section{Methodology: Accessing Everyday Performances of National Identity}

The methodology which underlies this study works from the assumption that an important (but largely overlooked) context for understanding the way in which national identity is performed is the individual life-history context. In other words, if we want to know how young people understand their national identity, we should in some sense invite them to perform it. Our strategy for capturing such performances was through a phenomenological research methodology. In short, we sought to capture the essential themes in the life stories our participants shared with us. In this section of the paper, we wish to first share something about the broader schooling context of the participants in the study, before turning to an explanation of the research methodology itself.

\section{Context for the Study}

Our research site for this study was a small charter school, Headwaters High School, ${ }^{5}$ located in an upper Midwestern city, with a population of approximately 280,000. The first author secured 
entry to the site and carried out the interviews with the participants. His primary entry to the school was secured through a social studies teacher, Edie. Edie is a white female, who had taught secondary social studies for approximately two years at the time of the data collection. The first author had been her primary methods teacher at the university where she obtained her teacher certification. In addition, Edie had participated in another research study that he had previously undertaken.

Largely white, and of a somewhat eclectic social class composition, ${ }^{6}$ the student body at Headwaters High School was nonetheless composed of students whose discussions of curricular and extracurricular events evinced a high level of engagement with both school knowledge and popular culture. For the three weeks the first author remained in the field, he daily observed the entire student body in one of two classes: "American Dreams" (an integrated high school American history and literature course) and "Revolutions and Conversions" (an integrated highschool world history and literature course). In both courses, the first author observed over the space of one curriculum unit. In "American Dreams," this was a unit dealing with the post-war United States. In "Revolutions and Conversions," this was a unit dealing with decolonization in China, India and southern Africa. These observations were meant to set some context for the interview data, which were the primary data-collection strategy for the study.

Headwaters High School is located in an industrial park, and although the outside of the building might reasonably lead one to imagine that this was a school, the interior looked remarkably unlike what people generally expect schools to look like: it had open spaces, with carpeted floors, and exposed pipes and ducts along the ceiling - what the first author called in his field notes a post-industrial atmosphere. The staff worked to create a family atmosphere within the building (one rather at odds with the built space itself); hence there was a common area with a student refrigerator and couches. Furthermore, students called teachers by their first names. Students felt free to take their shoes off, wear baseball caps, drink beverages during class, and use the restrooms without first asking permission. The school espoused for itself a Montessorian philosophy.

Through observation of all of the above, the first author came to view the research context as most decidedly hybrid. Like many other attempts at school reform, the "grammar of schooling" proved hard to alter for the staff of Headwaters High School (Tyack \& Tobin, 1994). Hence, the effect on the first author was one of slight dissonance, as students, faculty, and parents worked to negotiate the boundaries between social expectations, local control, and school reform. As it relates to the multiple contexts which frame this study, we would here argue that the students of this school - participants in this study - might usefully be viewed as inhabiting the borderland between school success and school failure. Clearly, they were at times willing and able to engage in school work, but appeared at other moments unsure of the rules by which, or unconvinced of the necessity, to do so.

\section{Methodology and Methods for the Study}

This study was phenomenological in general orientation. We turned to a phenomenological research methodology to both generate and analyze the data because it was a good match for the work we wanted to do in capturing our participants' performance of their national identity. For phenomenology, as van Manen notes (2001), "is the study of lived or existential meanings; it attempts to describe and interpret these meanings to a certain degree of depth and richness . . . 
[It] attempts to explicate the meanings as we live them in our everyday existence, our lifeworld" (p. 11).

Using a phenomenological research methodology helped us to better understand the particular, the concretely lived, and the everyday as it is revealed in common social practices - the actions Americans habitually undertake, the stories they habitually tell, and the groups and individuals to whom they habitually relate.

After a week of classroom observations, the first author invited all of the students in the two observed classes to write lived experience descriptions, or what Van Manen (2001) refers to as protocols. Participants were given a sheet of paper with the following instructions:

In the space below and on the back side of this paper, I would like you to tell me about a time in your schooling career when you felt like you understood what it meant to be an American. Just tell me the story in as much detail as possible. Tell me what it was like for you, the time, the place, what you were thinking at the time, and anything else you think would help me to understand your story. Thanks for your help!

We view these protocol texts as invitations into a conversational space - a conversational space that would be expanded in the interviews the first author would later conduct. These protocols also allowed the prompt to be tested within the local context, introduced participants to the nature of the research, and served as methodological tools for the subsequent interviews.

After collecting these protocols, all students were invited to become formal participants in the study by agreeing to be interviewed. Interviews with ten students, which were audio recorded, were conducted at the school itself in whatever quiet space could be found (often in the student lounge - a space as private as one could hope for in this research setting). ${ }^{7}$ The first author began the interviews by referring back to the protocols, and asked students to elaborate upon what they had written. As such, the interviews could commence with more ease, as participants had had time to reflect upon the narratives they wished to share.

In this study, then, the primary method for accessing the performance of national identity was the unstructured, phenomenological interview (van Manen, 2001). As already noted, the primary prompt used to invite the participants into their story-telling was the following: Tell me about $a$ time in your schooling career where you felt you understood what it meant to be an American. When expansion of the prompt seemed necessary, the first author also invited participants to talk about an experience that really seems to have marked your schooling. A good phenomenological prompt is easily understood by the participants, invites the detailed narrative telling of concrete experiences, and evokes an attitude of reflection on the part of the participant. We experienced success with these prompts, in that they drew out a variety of detailed and compelling responses - stories that seemed highly meaningful to the participants, and which they were excited to share with researchers.

Our interview prompts take advantage of light shed by previous research studies. First, we sought to avoid research procedures that too easily suggested to participants that they needed to talk about the nation and their national identity in relationship to a set of historical events. ${ }^{8}$ In the Barton and Levstik study (1998), as well as the Epstein study (2000), participants were given a pre-determined set of historical events and persons from which to construct their narratives. In the Mosborg study (2002), participants were given newspaper articles on national issues, as 
chosen by the researcher. Though research findings are always the product of research methods, we think it is important to remain reflexive regarding the impact research methods have on findings.

In addition, the interview prompt for this study takes advantage of the fact that discourses about the purposes of schooling nearly always contain a national or civic component (democratic citizenship, social mobility, international competitiveness, etc.). Therefore, we theorized that the stories students told would say something about how - and how well - those purposes are achieved. In particular, our interest was in the way in which students' everyday experiences at school - what Jackson (1968/1990) called the "unnoticed" world where we "encounter both friends and foes" (p. 4) - might impact the narratives participants would produce. Our goal was not to dismiss the importance of the enacted history curriculum the first author was observing. Rather, we felt instead that previous research has thoroughly uncovered the way in which classroom history instruction overlaps with the narratives students might produce (in particular, see Seixas, 1993; Seixas \& Clark, 2004; Wineburg, 2001). We, in turn, might leave more room for an exploration of the school as a civic institution, a place where power was both enacted and experienced, and as a potential curriculum of national identity in its own right.

The first author later transcribed these interviews for extended analysis. He interviewed ten students for the study - eight of whom we give particular attention to in the course of this paper. Within the complete set of interviews conducted, nine students were white and one student was black; six of the participants were female and four were male. Each participant was interviewed once, and interviews generally were from forty minutes to an hour in length. After having left the field, the first author contacted Edie, and invited her to announce to the class that any interview participant could review their interview transcript for accuracy or additions. No participants requested to do so.

In undertaking the lived experience interviews, the first author followed guidelines given for phenomenological interviewing. In such interviews, it is important to invite participants to dwell in their concretely embodied lifeworlds (Dahlberg, Drew, \& Nyström 2002; van Manen 2001). That is, the first author encouraged participants to put into a narrative format their own experiences, with as much concrete detail and context as possible. He also encouraged a narrative format to the experiential accounts by asking such questions as "what happened next?" When he sensed that the participants were speaking in generalities, he asked them to connect those general statements to a particular time and place. Following van Manen (2001), the research encounter was less concerned with the factual accuracy of any narrative than with the "plausibility of an account - whether it is true to our living sense of it" (p. 65). Validity, in this study then, does not refer to an accurate description of objective reality, but rather to our ability to provide an objective rendering of participants' lived experiences - that is, to an objectification of subjectivity itself.

At times during these interviews, it was quite clear that the ability to "truthfully" narrate and the desire to say the "right thing" were in conflict. Students know, after all, that they are generally supposed to say nice things about teachers, and that schools are supposed to be motors for social advancement - a discursive situation which Bakhtin (2000) describes as involving "authoritative discourse” (p. 342). Yet at other times, it was clear that the first author, as researcher, provided a new dynamic to schooling, a new position from which to speak, and in ways that seemed more honest - a discursive situation which Bakhtin (2000) describes as involving "internally-persuasive discourse” (p. 330). We tried to note those moments in each transcript and in this way another aspect of our data was opened up for analysis. ${ }^{9}$ 
Having collected and transcribed the interview data, then, we next turned to analysis. In analyzing these interview texts, the first author took the lead. He individually read through each interview account several times, noting the narrative structure used within each story: the characters who inhabited them, the thematic points around which they were structured, and the discursive patterns that ran throughout. He then spent time working across the various interview texts, rearranging initial words and phrases into common thematic categories, which in turn became the basic structures through which further interpretive work could be pursued. This initial phase therefore worked structurally, both within and across texts.

The next stage in phenomenological analysis involves the separation of essential from incidental themes. Phenomenological coding does not so much rely on frequency of occurrence; instead, the first author determined the data's essential themes by moving back through the texts and writing down words and phrases from each story that seemed to him particularly evocative what van Manen (2001) has called the "highlighting approach" to doing phenomenology (p. 94). Here, then, an approach to phenomenology that draws from hermeneutics was employed, one that posited meaning as emerging from a circular reading of whole-parts-whole. The first author therefore spent time moving back and forth between the structural reading of the set of interviews and those aspects in each individual text that were deemed essential to the lived experience.

At this stage in the research process, the second author joined into the data analysis. After much discussion, we posited one theme as essential to all the lived experience accounts. That theme we named:

1) The Teacher as a Nation-Building Curriculum.

From there, we noted several essential subthematic variations, ones which, while not moving across the entire data set, are all in obvious ways related to the principal theme. Those themes we have named:

a) The Nation Lived as the Threat of Abuse;

b) “Individual” Life Failures Lived as National Freedom and Privilege; and

c) The Nation as it is Made Familiar and Personal.

As diverse as the stories narrated to the first author were, these themes speak to the experience of American national identity within this particular context.

We strongly agree with Max van Manen (2001) that the act of writing is an integral part of the phenomenological research process - not just something done after the research process is itself over. As he notes, "to write phenomenologically is the untiring effort to author a sensitive grasp of being itself - of that which authors us, of that which makes it possible for us to be and speak . . . in the first place” (p. 132). It is in the writing phase where we as the two co-authors of this paper most closely worked together. We did this by discussing ideas and problems, stylistic and data representational strategies, and numerous drafts of the manuscript - all in an attempt to share the stories and voices of our participants within the limited space afforded by a journal manuscript.

\section{The Teacher as Curriculum: Presentation and Analysis of the Research Data}

The students who participated in this study were not what might be considered typical students, in that they had all chosen to attend a charter school with an open, liberal orientation. Students came to this school with a variety of previous schooling experiences. Some had gone to small religious schools; others had gone to charter schools their entire scholastic career; and still others 
were coming out of the standard public-schooling track of the city in which they lived, having attended a neighborhood-elementary school, followed by one of the city's comprehensive junior high schools, and finally, some of them attended one of the city's seven comprehensive senior high schools (or followed such a track in one of the city's surrounding suburbs).

These students and their families were therefore consumers in the contemporary educational marketplace. As one could perhaps speculate that most of American society's most conventionally-successful students would probably not be drawn to a small charter school, with its much more limited curricular and extracurricular offerings, the students who participated in this study might therefore be seen as forming a distinct subgroup, in that they have taken advantage of the reconfiguration of the public schooling landscape. It would perhaps not be surprising, then, to find that these students were in many ways dissatisfied with the status quo of mainstream American schooling, and perhaps even with American society in general. We shall soon show that in many cases this is precisely so.

Yet despite the location of this researcher encounter - among students whom one might predict were critical of mainstream American schooling - the meaning of the national identity that eventually emerged in these accounts was rather much darker than we had expected. It was also much more intimate. For these students, American national identity, as transmitted through the schools, was not an amorphous feeling of patriotism or love, nor was it much connected to subject-matter curriculum; rather, we shall see instead that it emerged through a series of interpersonal encounters with significant adults in their lives.

This adult figure, in eight out of ten of these accounts, was a classroom teacher. ${ }^{10}$ We find this significant, and it therefore was identified as the overarching thematic point around which to organize the analysis presented in this study. Since the rise of the standards movement in the 1990s, which itself coincided with a renewed emphasis on content knowledge in teacher preparation and research, we feel that the teacher qua teacher ${ }^{11}$ has received too little attention. Our analysis, therefore, very much focuses on what we feel is an area of the curriculum that has received far too little attention to date - the curriculum that emerges as students spend time learning to make sense of, tell stories about, and react to the actions of, their classroom teachers. We will therefore attempt to call attention to the importance of the tact and acumen - or lack thereof - with which classroom teachers mediate the everyday experiences of schooling for their students, all the while explaining the vision of America that emerges in this process.

\section{Primary Thematic Finding: The Teacher as a Nation-Building Curriculum}

Though scholars, parents and teachers might often assume that the world of teenage students is dominated by a peer curriculum and a variety of entertainment media, in this section we will attempt to show just how important teachers and other adults figure in the experiences of the participants in this study. The nation, as understood by the participants in this study, was intimately attached to the words and actions of the authoritative-classroom figure - the teacher. We know of no research that has attempted to unpack the role that the "image" or "text" of classroom teachers has played in the learning of students. ${ }^{12}$ Our own work might be seen as a first attempt in that direction. ${ }^{13}$

The importance of teachers in these accounts comes with some danger - for classroom teachers in these stories are never figures of no account. They may sometimes lurk at the margins of a story. This was the case for Molly, whose account ended with the rather unstable figure of 
her fourth-grade teacher:

I didn't really like her, she was really, like, angry, yeah, I think she just felt a lot of anger. Her husband had died like a couple of years before that . . . And she, I remember she had like this stool that she would sit on, and read a book to us. I just remember her, and she was like kinda tall and stocky and like short blond hair with bangs and glasses, and she talked real funny, and she, I don't know, she was kinda like not a favorite for anyone, you know? Just because she was so, and she would yell at you sometimes, she would scream and yell and just go off, and like, it was kinda not really healthy at all.

We will pick up the thread of Molly's story below, but for now, suffice it to note the power of this image of the teacher, and its strange juxtaposition within a story about America.

At other times, the teacher is central to the account - an almost beloved figure. This was the case for Naomi, whose entire story revolved around her respect and admiration for her eighthgrade social studies teacher, who would reward students for good civic acts by allowing them to lead the Pledge of Allegiance:

And I had a teacher who like, every morning, he would ask us what we had done to help the environment that day, whether we had rode our bikes to school rather than driving and stuff like that ... and like whoever had the best good citizenship story got to say the Pledge on the telecom, on the PA system . . . He lived on Rice Street or something, and the school was [quite far away], and he would tell us that he biked to school every morning, and we were like so in awe of that ... I think it was because he made it sound so noble, to drive down the gas prices and stuff and not using gas and stuff. Like help the environment, he just made it sound really noble. Our duty, you know, I was like fourteen or something.

For Naomi, the teacher was a text, one that was read eagerly. Naomi was a good reader of her text, for even in this small excerpt, we see her knowledge of something rather private about her teacher (where he lived). Such reading was put to use in order to in order to perform civic acts which would in turn please the beloved teacher; for while "there were kids who were like, 'I'd rather play my video game,' you know stuff like that . . . there were [also] kids like me, who were like, we always competed.”

Aside from where teachers turned up in these stories, there are two related issues that we would like to analyze in this section: 1) the degree of personalization of the teacher-figure in the story narrated; 2) the manner in which the teacher-figure acted to either include or exclude the child from the workings of classroom and school communities. As might be expected, the degree of personalization is related to whether the teacher figures centrally or marginally in the story presented. But such personalization also is related to another aspect of these stories, for far more personalized teacher-figures act in ways which protect students, by gently helping them to feel good about the communities of which they are already a part. It is in this last aspect that the teacher's nation-making role most clearly comes out, and that will require the most unpacking.

Katie's teacher was among the most personalized in the stories narrated. Her first-grade teacher was spoken about with glowing enthusiasm, and such enthusiasm built steadily as the story progressed: 
I think first grade was my favorite, because I really liked the teacher. [First Author: Why did you like him or her?] She was really young, and I think she had kids, she must have had kids that were about our age, because she knew exactly how to talk to us, she was really good at story-telling . . . I guess she just really knew how to make that connection. And she knew what was like the fashions and what was in at that time for little kids ... And the little kids always wanting to have the flared jeans, like the teenagers did, and, she wore flared jeans, so everybody just loved her, she was really nice ... So she was really, really nice ... [First Author: So none of your teachers now are as cool as this teacher?] I have yet to find a teacher that was as cool as my first grade teacher.

Being so cool was about fashion, but it was also about respect and understanding of the firstgrader's lifeworld. For example, this teacher allowed children to play with their toy-pets during naptime, and, as noted here, she talked to students in ways that seemed, in retrospect, just right.

Such a relationship meant the teacher-figure was better able to intervene in the world of social relations. In the case of Katie, this happened with great force during her first-grade school Halloween celebration. In sharing this part of her story, Katie begins by noting that “we didn't have very much money when I was younger, so we had to make [our own Halloween] costumes." In Katie's case, she used a plastic garbage bag and balloons to costume herself as a bag of jellybeans - a somewhat comic image on the surface. Yet the inability to buy the prefabricated costumes of monsters and superheroes, so common in mainstream U.S. culture, and which her first-grade peers were likely wearing, led to a moment of deep embarrassment: for after participating in the school parade, Katie noted that "I cried . . . because somebody's grandma was laughing at me, and I thought she was making fun of me, but she just thought it was cute, so I started crying."

The twisting and uncertain syntax of this sentence ("but she just thought it was cute, so I started crying") reveals at its core the power of the teacher-figure to intervene in its lived meaning:

Well, she looked at me, and I don't know if she was with somebody's parent or another grandparent, but they kinda pointed over towards me, but they were actually saying, "oh look how cute that costume is." Being seven-years old I thought they were pointing and laughing at me, so I started crying . . . [First Author: Did anyone notice?] The teacher came, and she wondered why I was crying, and then she was the one who explained to me that they weren't laughing at me, they were thinking that my costume was cool. And then she told me that I had the coolest costume in the class because I was the only one, like there were a lot of kids who were Spiderman, there were more than one, and a lot of girls are like fairies, but I was the only bag of jellybeans. (italics added for emphasis)

The teacher-figure in this story acts swiftly and tactfully. She reassures Katie that her costume was unique, something of which she could be proud. In the process, she gently addresses the underlying fear about social-class status that seems so prominent in this story. Katie's joy in reading her teacher, in understanding her as text, fully enabled this later moment, whereby her teacher maintained for Katie a sense of rightful identity and belonging in her community. 
This story of teacher as healer and maintainer of community can be powerfully contrasted with the story of Joe. While Katie's teacher was highly personalized, Joe's teachers appear as nothing more than a set of highly automated evaluating machines, ones who were determined to diagnose and correct his seemingly hyperactive behavior:

I was about in second grade ... I was the type of kid who was always running around the classroom or messing around, trying to avoid doing the work. And then once I got the medication, teachers actually walked up to me, asked me how, like they didn't really, like, when you are younger, they didn't know I was taking [the medication] quite yet and so they were wondering how I was able to control myself . . . Because we hadn't told them I had started taking [the medication], they had me tested, but they never told them I was taking it.

The consistent use of third-person plural pronouns to describe teachers and doctors is quite stunning here. Even though Joe, as the first author later clarified, was in a typical self-contained elementary classroom, the experience of a "they" judging him was paramount in this narrative.

Joe was quite pleased with the medication and the effect it had on him - not so much because of any personal goals it allowed him to accomplish, but because it pleased his classroom teacher:

Well, I was always with the bottom [reading] group. I was never able to pay attention in reading and that kind of stuff. So like, she was, my work got so much better. And she wanted to move me up the next [reading] group, and she was just wondering how I had improved so much, because there were some other kids with the same type of thing, and they [sic] were wondering if it would maybe work for them ... A And she was wondering, like how big of a change it had made for me, and she was wondering if she should have a lot of the other kids tested.

When the first author explicitly asked Joe to connect his story to being an American, he noted that "most of the other kids who were behind in like reading and stuff, they were from other countries, and didn't speak much English. I felt bad that I couldn't keep up, I felt that I was way behind, that I needed a lot of help." The implications of this story and the research context out of which it emerged are many. We would just observe the fact that the teacher(s) acted in ways that made Joe feel "more American," but that such actions came via a regimen of medication that allowed Joe to escape his placement in a low-ability reading group.

In drawing from these four accounts, it has been our purpose to demonstrate the centrality of teacher-figures in participant stories. As such, we are allowed to see the real power of classroom teachers as agents of care. Indeed, in our last two examples especially, we have sought to show the ways in which our data reveal that the teacher is herself a curriculum, one that is extremely mis/educative for students. This curriculum is in many ways a very basic one, for these stories speak ultimately to issues of social conformity, normalization, and shame. In thinking about schooling experiences, which revealed the nature of being American, our study participants avoided talking about subject matters such as history or civics, and instead spent time "reading" their teachers. As such, we find it helpful to think about this teacher-figure as a powerful agent for the (re)production of an American national identity. 


\section{First Subthematic Variation: The Nation Lived as the Threat of Abuse}

Clearly, in the four accounts discussed above, we saw elements that might be characterized as abusive. Certainly, Molly's story at least hints at the possibility of a teacher who is not relating to students in positive ways. Likewise, Joe's story points us in the direction of a teacher who is not acting with tact, who is letting her desire for academic achievement override her judgment about the best manner of addressing a child who is coming to grips with a disability. Yet just as clearly we saw teachers intervening to prevent a certain sort of abuse (Katie), and we saw situations that were generally non-abusive (Naomi). Hence, the need to turn to subthemes - distinct subsets of experiences which emerge within the overall analysis of "teacher-as-curriculum."

In this section, we would like to introduce and dwell upon Bethany’s story. ${ }^{14}$ Her story, along with those of Katie, Ian and Sophia, ${ }^{15}$ was one of threatened abuse, and in the case of Bethany, this abuse happened on several levels. Near the start of the interview, she moved to bring up her opposition to the War in Iraq:

Originally, I was like in fifth grade when we went over there, but the reason I thought we were going over there was because of the terrorist thing that happened, but lately I haven’t really heard anything about Osama bin Laden. Like all of a sudden it's like Saddam Hussein . . . Everybody thinks if you don't support that, you are not being an American. Like, I don't agree with that . . . Like, if you don't support the war, you're not for America. I don't know, that's not how I feel about it.

This might seem like a rather ordinary thing for a participant to say, given that debate about the War in Iraq was intense and protracted, and certainly played a role in children's lives during this time.

Yet the transition from this set-up, to the experience itself, reveals the lived component behind Bethany's above statement. For in response to a general probing question, Bethany quickly moved into the heart of her story:

Like at [my former schools], I remember a lot of my teachers who like, well, not a lot of them, a couple, who were, like my math teacher, when they were taking down the little statue thing, he made us watch it in class. ${ }^{16}$ And he was like, "well if you're not going to support the troops and you're against us then you can get out of our classroom.” [First Author: Really?] I was like, "What?” [Bethany laughs]. You can’t do that. And I was surprised that nobody said anything. [First Author: Nobody said anything?] I didn't want to get kicked out of class because I'm not great at math. So I just kinda sat there quietly, but I was like so shocked that he said something like that. I didn't think that teachers would say stuff like that.

In ways no less clearly than above, Bethany here reads her teacher as a text, and learns certain things about the U.S. in the process. Indeed, the nation building done in such circumstances is an all too familiar one - a unity enforced at the price of the stifling of dissent.

In such a way, Bethany experienced a double threat. First, her right to dissent against the political opinion of her teacher and the actions of her government was taken away from her. 
Second, her right to an education in mathematics was taken away, as her teacher apparently decided that class time was better spent in watching this bit of news unfold. As she noted:

I just remember he had the TV on because this is the class I had after lunch. And so we walked in from lunch, and he was watching it, and we just sat down, and he was like, "we are going to watch this ..." and he went on and made his little speech. I was like, “I don’t feel comfortable watching this in a class with you. I don’t want to watch this. I don’t support it. I don't care” . . . He was taking away my education because I really suck at math [Bethany laughs]. No, seriously, UH! [First author and Bethany laugh]. I couldn't afford to, like I had missed a lot of school, and I couldn't afford to miss class for another day . . . Because that's a person who can basically do whatever they want with the grade. Like, he can say I didn't turn such and such in, and I did. I've always thought that way, I don't want to have something go wrong.

Bethany attributes almost infinite power to the teacher(s), the ability to "do whatever they want" with the grades - grades that are a real determinant of a child's future. The opposite of such infinite power is an experience of extreme helplessness and vulnerability, so characteristic of Bethany's lived experience, and in other such cases where abuse goes on without the victim feeling safe to speak out.

\section{Second Subthematic Variation: "Individual" Life Failures Lived as National Freedom and Privilege}

With the case of Bethany, national unity comes at the price of an abusive assimilation, one that would permit no space for disagreement or dissent. As such, the experience is lived as highly negative. Our second subtheme is paradoxical, for the stories, on their surface - as with Joe's account above, which we would categorize under this same subtheme - are happy stories of social mobility, personal freedom, and national privilege. Yet underlying the surface feelings, there exist deep wounds - the internalization of social inequity, generating in turn feelings of personal inferiority. Hence, one overriding question to unpack here is how a sense of personal inferiority can coexist with that of national privilege.

Let us start by returning to Molly, who we have previously met via her portrayal of her fourth-grade teacher, who she characterized as "not a favorite for anyone," as a teacher who would at times "scream and yell and just go off." This story of a teacher who appears unstable before her students actually began as a story of guilted privilege, where Molly notes:

OK, well, I remember at the elementary school I used to go to, sitting in class and thinking about where I am, and like living in America, and going to school, and I think it just kind of hit me, you know. Sometimes I kind of struggle with the fact, that I'm so privileged, that I'm like having this education, and I'm not really helping people, you know. Like I'm not helping them get an education. So then I just kinda think about it in terms of, well, I have to finish this high school, graduate, and then go on. So first I need to prepare myself. But I don't really know if I like, if we learn what I need to. You know, maybe I waste my time here, 
in limbo, when I could be doing that now.

Hence, Molly's deep desire to serve and be useful to others is stymied by her schooling experience - one which presumably focuses too much on the self, and not enough on engaging with the needs of others.

What brought on this struggle over feelings of both privilege and guilt? As the first author and Molly explored this experience, the following exchange occurred:

[First Author: So you're sitting in class and you look outside, the window. Is that right?] Yeah. [First Author: Do you remember what you saw when you looked out the window?] I was like on the second floor, and I had a seat by the window, there was trees, I don't know. It was a really hot day. I was just thinking about how, like, my problems in school aren't nearly as bad as other peoples' in the world around me. [First Author: Were you having problems in school?] Well, I don't know, I wasn't really like doing very well. My teacher was a little more traditional. Like, it wasn't like [it is here]. I didn't understand some of the math and stuff. That's when it started to begin that I didn't understand stuff. [First Author: That's when what?] That's when it started to begin that I didn't understand, before that I was fine. [First Author: That's when you seriously began to start thinking about dropping out?] Yeah, it was like, why am I here? I think there is so much more.

The inverted nature of Molly's experience - a sense of privilege brought about through a perceived personal "failure" or "inability" - speaks very much to a key strand of experience identified in this study.

Though she violated no rules, did nothing that would land her in trouble, Molly did in fact feel some guilt even in telling the first author this story. In fact, after the interview was over, she came back to find the first author to tell him that:

I just want to say one more thing. Like the day when it hit me and everything, it's probably one of the reasons why I thought she was angry, because I was thinking about what I like believed in and everything. I don’t even really know my teacher, I didn’t have an opinion about her.

All evidence to the contrary, Molly claims that she "didn't have an opinion about [her teacher].” We see that Molly is here, in some sense, punishing herself for her own freedom to think differently from the teacher ("I thought she was angry, because I was thinking about what I like believed in”). The privilege with which she opened her account was, in this case, to be engaged in work she did not like, with a teacher whom she did not trust. In this, she felt she had it so much better than other students around the world.

This paradoxical view of the privileges of being an American was likewise mirrored in the texts of Connor and Noah. For these two boys, being an American was to be surrounded by a treasure-trove of riches - yet, strangely, to lack the desire to unlock it. For example, Noah, whose experience at an alternative school - one where attendance was optional and the curriculum was apparently at the sole initiative of the student - led him to state the following: 
There were a few classes, not many, there wasn't like a structured math class, a structured reading class, like that. But that didn't really happen much. A lot of students just kind of sat there and did nothing and they played poker. [First Author: Played what?] Poker [Noah laughs]. I'm good at poker now, but it seems like you do the same thing day after day and then looking back . . . [Noah pauses] Americans are kind of lazy. In my opinion, it's because we are overwhelmed with choices. Like you didn't do anything for long [at that school], there were like ten different classes. It's a hard choice, cause you didn't know what to start with. Most people just have trouble managing their time. I'm bad at it too. I'll say I'm going to do something, and then I'll put it off. But it feels like an American, just to have so many choices. I can do anything with my life. I don't know what I want to do with my life. But in some countries you don't have a choice, you have to do a certain thing.

There is a certain wisdom to seeing that a multiplicity of life choices is no guarantee that any of them are worthy. Yet for Noah, that seemed not to be the point of the narrative. Rather, the concerns he later shared were with acquiring "the basic skills you would expect for students" things he felt would help in college, like "how to write papers" and "how to do a PowerPoint." Hence, choice - while still the quintessential marker of being American - was not so much a positive good, but a distraction, something to be avoided as one works toward the credentials needed for college and work.

Connor, whose narrative centered on the importance of toys and games in his life, ${ }^{17}$ more clearly framed choice as both an existential dilemma and a national privilege:

it does help that you have a good education . . . but there have been like some people, who have opportunities, and like they take them, it's like they have a natural intuition for something, like, if they have really good designs for toys, and they've never learned like math for graphing, instead of having a good job, like somebody who had had an education, they just end up like being like a cartoonist or something, because they don't know how to design and build it, they can't measure out the dimensions, I guess they never learned how. But if somebody has that education, say they have a big career in the Lego industry, or something like that, designing toys for them.

Hence, something like math ${ }^{18}$ would enable one to get the job one ultimately wanted. If one wanted the best job in the toy industry, certain wise choices would need to be made along the way.

Yet ultimately, for both Connor and Noah, these choices - both as privilege and as dilemma - were uniquely America. Connor stated at the very beginning of his account that:

The American Dream is all about having opportunities because, like, at every school I've ever gone to, there have been more opportunities than, like, you would have got by being in other countries. And I've only ever been out of the country, like three times, and I've never seen any other schools in my life, but you hear it all the time, on the news or whatever, there's such little opportunity wherever . . . But if I lived in like, Afghanistan, at the very very most I would get to take the 
classes that were necessary.

One could compare this statement to Noah's claim:

there's like places where you can't get an education. You have to do the same job, like you pretty much just have to become a doctor. There isn't an ability to choose that at all. So I think that's what it means to be an American.

That Noah could transport himself to a discursive space where doctors are produced in places "where you can't get an education" seems to imply that in places where you can get an education, becoming a doctor is simply a matter of personal choice - that there are no social determinants on career or income. Hence, whatever failures exists in the US - including one's own - are seemingly a product of choice, or of not choosing. The alternatives become rather stark: one can either start to critique the system that produces inequality (an option missing in these accounts), internalize the inequality as "lack" or "failure" (as Molly and Joe did), or ultimately see one’s self as "kind of lazy" (as was the case with Connor and Noah).

\section{Third Subthematic Variation: The Nation as it is Made Family (ar) and Personal}

For our last two accounts - those of Naomi and Eileen - the teacher figured in the story is beloved and rather central to the account. Yet the protections these teachers provided were not of the kind for which we as researchers would hope: for they preserved these students in a type of pre-political innocence, one where bad people do bad things, and good people do good, and the nation is imagined as a type of family that sticks together through thick and thin. As such, it helped to position their current schooling experiences at Headwaters High School as hypercritical, if not a bit unpatriotic.

Across six of the ten stories collected, the prominent American national events of the first decade of the twenty-first century are an omnipresent horizon: the tragedy of September 11, 2001; the search for Osama bin Laden; and the wars in Afghanistan and Iraq. Only in the cases of Eileen and Bethany are any of these events central to the story of what it means to be an American, yet in all cases these events are made sense of through lens that are personal and experiential. Hence, like the respondents in the research carried out by historians Rosenzweig and Thelen (1998), our own participants "made national stories personal" and "personal stories national" (p. 126).

This comes through most clearly in the story of Eileen, which was a recounting of the lessons learned on September 11, 2001 - when she was in the fifth grade. In her telling of this day, the dominant theme is of family - her own, others, and indeed, the nation itself as a sort of family. As she noted:

Like when I heard that the plane hit one of the towers, that's when I finally got, like I was just shocked. Because I wasn't sure what was going on, you know, a plane full of people, you know, hit a building full of people. So that means obviously a lot of people died. And you know, for me, it like affects me, people, if I like hear about people dying, stuff like that, I mean, I don't know, I almost get 
kind of sad for them and their families. Cause like, you know, like when my family members die that's really sad. And you know I get kind of depressed about that. So if like, you know, when I remember how I felt when a family member died, so I feel bad for the other people.

Even in retrospect, unable to see the myriad of ways in which this event implicated us all in global processes and events, Eileen's use of the nation-as-family trope becomes the only way she had for drawing connections between her own position and that of others.

Family, as the institution that most clearly stands between citizen and state; therefore becomes the discursive pathway towards making sense of the national. The person who might have been able to help her make better and richer sense of this was her classroom teacher. For as Eileen notes throughout the account, it was with him that she watched the events of that day unfold on the television. Yet rather than discuss the events - about which Eileen and her classmates were variously "curious," "shocked" and "confused" - the teacher proceeded with his normal lesson. Hence, Eileen is left to make sense of it through her own family(ar) discourse of the nation:

Well, it had like, it didn't have that much of an impact on me, like a lot, like at the time ... And with that happening it affected the country a lot . . . because you know a lot of people's families were affected. And so it was sort of like it affects the rest of us, cause we think, what if it had been our family . . . It's like a nice thought, like, “oh, we're Americans, it's like what does it mean, what does it mean to you to be an American?” And it's kind of like being in one giant club . . . You learn what it's like to be a part of that group of people, part of that almost one giant family.

Nearly five years later, in the ninth grade, Eileen's account gave little hint that the nation was anything but an abstraction, a collection of families, who would naturally come together when times were tough. The space for dissent and debate within such a framing would not, we assume, be prominent.

Ultimately, it is this distrust of dissent and debate which seems to reside in these all too family(ar) narratives. Even with Naomi, whose own beloved teacher rode his bike so as to drive down gas prices (and perhaps render mute the need to go to war in oil-rich countries), dissent bordered on the unpatriotic. As Naomi would admit in her interview account:

I honestly get the impression here, we don't say the Pledge, and we don't have flags up in our classroom either. In our last school, it was like imperative that every classroom had a flag and that the flag was higher than whatever else was in the room, near the ceiling. I don't know, this school is more liberal, and like, "we want you to think for yourself," and especially with all the controversy about the Pledge, with the whole under-God thing, and a lot of people are like resistant to the idea of America, like resistant to what American's doing in Iraq, like as a country. I don't know if I should tell you this, but a lot of our teachers are, well they don't hate America, but I guess I never thought about the fact that I could see things wrong with America, because when I was younger, it's the land of the free, home of the brave, and there are so many opportunities here, we're capitalist, 
democracy, and have it so much better than a lot of other places in the world and stuff. (italics added for emphasis)

While Naomi hints that she is emerging from a family(ar) consciousness about the role of dissent in a democracy, she still rather strongly suggests that her teachers might be "resistant to" or "hate" America for opposing the war and not displaying flags in their classrooms. That such a lesson might be derived from one's experiences in American schools does not make us overly confident about the civic education happening there.

\section{Conclusion: Opportunities for Resistance within Acts of Collective Memory}

One issue raised by this paper has been the manner in which educational researchers might best think about national identity and the school's role in its transmission. In this study, we were interested in narratives which would reveal the way in which national identity is itself performed - what we might call, drawing upon phenomenology, the experience of the "lived nation." ${ }^{19}$ In making this turn towards the lived nation, we have sought to demonstrate the "fused" nature of national and personal histories: that "the nation," as an imaginary construct (Anderson, 1983/1992), one that is given meaning through routine and "banal" markings that make of it an “endemic condition” (Billig, 1995, p. 6), gains its meaning through local, concrete, embodied instantiations of it.

When - as many of us have over the past year - we read the life story of a figure such as U.S. President Barack Obama (2004), we naturally tend to read in a "fused" manner, one that alternates between the particularities of lived experience and the overarching metanarratives of national progress and decline. Traversing any text in this way requires overcoming a tendency to read the world in an overly structural manner - where the personal remains distinct from the social. For educational researchers, it means overcoming the tendency to understand subject matter as distinct from its potential pedagogical enactments, by real flesh-and-blood teachers, ones who are managing much more than subject-matter considerations at any one point in time.

If we take seriously the notion that the nation gains meaning as it is locally lived and embodied - the lived or performed nation - then a more post-structural understanding is needed for us as teachers, researches, and citizens. Following thinkers such as Baudrillard (1995), we might suggest recasting identity - and the "texts" from which they are produced - as Möbius Strips. ${ }^{20}$ Like the fantastic staircases of M.C. Escher, in the world of the Möbius Strip, as long as one keeps moving (the "flux" of everyday lived experience), one eventually traverses both the "top" and the "bottom," returning to where one started - but embodied now in different, perhaps richer, ways. Such is how we see the relationship between the personal and the national, the individual and the social. In such a world, submission can turn into resistance at a moment's notice, because identity is itself hybrid, anchored in multiple subject-positions, composed from multivoiced stories and discourses.

The tension between resistance and submission speaks, then, to issues of multivoicedness. The stories told by the participants in this study reflect ambivalence towards the hegemonic narrative of American national identity - the "quest for freedom." For through the exploration of narratives of the lived nation, we find the participants of this study working to reconcile the sanctioned national narrative with their own lived experience. The difficulty that so many of them encounter in trying to do this results in the strong feelings associated with these stories, as 
well as their lasting impact in identity formation. In this ambiguity, and the strong feelings such ambiguity produces, we can view these narrative performances as the shifting forms from which students might more clearly cobble together a sense of resistance to that which produces social injustice.

Viewing these narratives of schooling as forms of resistance, we are still left though with the question of what forms of citizenship these participants are likely to enact in the future. This suggests some questions for future research. If, at any particular moment in time, students' narratives of the lived nation can be characterized by the "quest for freedom," what role do they see for themselves in continuing to pursue and advocate for these freedoms? Alternatively, if students' narratives are better characterized by a sense of betrayal or abuse (as we have suggested is clearly sometimes the case), what possibilities can students envision for themselves in resisting, overturning, and changing these trends?

High-stakes testing, standards-based reform, various movements towards individual and institutional accountability, and even research overly focused on teacher content knowledge these phenomena have all tended to cast a relatively large shadow over the everyday pedagogical and classroom management practices which make up a large portion of the school curriculum. Our findings here ultimately recall attention, then, to the importance of the person of the teacher: her knowledge of subject matter and instructional practices, to be sure, but more so to the tact and acumen with which she mediates the everyday experiences of schooling for her students. Until the time comes when teachers are trusted with matters of curriculum and assessment, such tact and acumen may be, in the words of Dewey (1915/2001), "the deepest and best guaranty of a larger society which is worthy, lovely, and harmonious” (p. 20).

\section{Endnotes}

${ }^{1}$ Of course, debates about American exceptionalism pre-date Wertsch and O’Connor. However, this is the first empirical study we know of that attempts to study how the layperson actually thinks about the history of the United States and hence, by extension, U.S. national identity.

${ }^{2}$ Mosborg's research is particularly important, for it reveals the role of social context in the performance of national identity. Participants in her study constructed national narratives of both decline and expansion depending upon the prompt given them - different aspects of their background experience and personal identity emerging depending upon the research prompt provided. While Mosborg does not dwell on these reversals, her research is pathbreaking in showing how one's social context impacts the past one is able to recall and the identity one wishes to accentuate at any particular moment in time.

${ }^{3}$ The distinction between other-directed and self-directed narratives belong to Wertsch and O’Connor.

${ }^{4}$ A critique we might levy here is that researchers in history education have let the dominance of their disciplinary frame overly inform their reading of American national identity among students. That is, in trying to examine how students use descriptive and evaluative language about the past (crudely, the language of the historian), they ignore the plethora and power of the normative statements about national identity that populate the present. Such narrative statements 
can produce a very different read of how students think about national identity - something which this paper seeks to demonstrate.

${ }^{5}$ Pseudonyms are used throughout this paper for participants and sites.

6 This statement was initially built largely upon the first author's impressions. To confirm the impression, he reviewed the web pages devoted to Headwaters at the school-choice website, greatschools.net, which stated that the combined student population of both Headwaters junior and senior high schools was $74 \%$ white students, $10 \%$ black students, and $7 \%$ Asian students. The percentage of students eligible for free and reduced lunch is listed at $7 \%$, with the website stating that $30 \%$ eligibility is the state average. The entire student body of the high school was under 200 persons.

7 The first author attempted to maintain some degree of interview privacy to the degree possible, though the open nature of the school made that at times rather difficult. So in addition to performing for the first author, interview participants may have also been performing for peers at certain points in the interviews. For example, as will be seen with Ian, who spoke with great animation and regularly swore, it was difficult not to have his peers glance over from time to time. Teachers were never present when student interviews took place and so were never an audience for these interview performances.

8 Though speaking of historical events - by way of experience in the history classroom, for example - were of course not ruled out by the prompts. Indeed, we shall see that several participants did make reference to recent "historical" events, such as 9/11 and the War in Iraq.

${ }^{9}$ A good example of this is in Molly’s account, where it took much patience for the full nature of her story to come out - and even then, Molly seemed greatly conflicted regarding what she had to say about her teacher.

${ }^{10}$ In Ian's accounts, school administrators and safety officers were the prominent adult figures. In Sophia's account, National History Day judges and the participant's mother emerged as the main figures of the account. Had we more space to elaborate on these findings, we would attempt to show the manner in which these adults were themselves figured as teachers in the accounts given. However, lacking that space, we will instead just categorize these two accounts, and refrain from drawing from them for purposes of data analysis.

11 Or what we would call the teacher-as-pedagogical-caregiver (Noddings, 1992; van Manen, 1991).

${ }^{12}$ We understand "learning” as something very broad here - not just what students know (about history, about math), but what they believe, what they feel, and how they wish to live their lives. Regarding research on the image of the teacher and its role in such learning, we would like to acknowledge the important role that studies on the cultural imaginary and the situation of teachers within it have played in our own work. See Britzman, 1986; Dalton, 1999; Grumet, 1988; Hogan, 1990; Judge, 1995; Van Manen, 1991; Weber \& Mitchell, 1995. 
13 See also Erickson \& Schultz, 1992, for their analysis of the role of teacher attention in student experience of the curriculum. In particular, their metaphor of teacher attention as a type of prison spotlight - sweeping, momentarily fixing, before again moving on - we find suggestive.

14 Bethany was the sole black student in the study. While race certainly plays a part in her story, it is also, of course, not the whole of her story (indeed, we can and should say this about the white participants in the study as well). Given limitations of space, we cannot take up this aspect of the analysis in this paper.

15 Katie's story was fully analyzed, for our purposes here, in the first section. See footnote 10 for more on Ian and Sophia, and our reasons for not analyzing their stories.

16 A reference to the staged destruction of the Saddam Hussein statue in central Baghdad, on April 9, 2003.

${ }^{17}$ The first author's interview with Connor did not produce a story in the conventional sense of the term. Rather, Connor used the interview space to talk about his continuous movement from one school to another, his search for school success, and the distraction which his personal interests posed in working towards that success.

18 Though it is beyond the scope of this paper, the role of the math curriculum is obviously central to many stories here, in particular, those dealing with failure, credentials, and privilege.

19 The notion of the lived nation can be compared to other recent formulations which seek to show how large social categories - such as gender - are taken up and internalized through individual performances (Butler, 1990/2006).

${ }^{20}$ According to the Oxford English Dictionary, a Möbius Strip is “a surface having only one side and one edge, formed by twisting one end of a rectangular strip through 180 degrees and joining it to the other end.”

\section{References}

Anderson, B. (1992). Imagined communities: Reflections of the origin and spread of nationalism (rev. ed.). London: Verso. (Original work published in 1983)

Bakhtin, M.M. (2000). Discourse in the novel. In M. Holquist (Ed.) and C. Emerson \& M. Holquist (Trans.), The dialogic imagination: Four essays by M.M. Bakhtin (pp. 259-422). Austin, TX: The University of Texas Press.

Barton, K.C. \& Levstik, L.S. (1998). “It wasn’t a good part of history:” National identity and students’ explanations of historical significance. Teachers College Record, 99(3), 478-513.

Barton, K.C. \& Levstik, L.S. (2004). Teaching history for the common good. Mahwah, NJ: Lawrence Erlbaum Associates, Inc., Publishers. 
Baudrillard, J. (1995). Simulacra and simulation (S.F. Glaser, Trans.). Ann Arbor, MI: University of Michigan Press.

Billig, M. (1995). Banal nationalism. London: Sage Publications.

Britzman, D.P. (1986). Cultural myths in the making of a teacher: Biography and social structure in teacher education. Harvard Educational Review, 56(4), 442-456.

Butler, J. (2007). Gender trouble: Feminism and the subversion of identity. New York: Routledge Classics. (Original work published in 1990)

Cornbleth, C. (2002). Images of America: What youth do know about the United States. American Educational Research Journal, 39(2), 519-552.

Dahlberg, K., Drew, N., \& Nyström, M. (2002). Reflective lifeworld research. Lund, Sweden: Studentlitteratur.

Dalton, M.M. (1999). The Hollywood curriculum: Teachers and teaching in the movies. New York: Peter Lang Publishing.

Dewey, J. (1997). Democracy and education: An introduction to the philosophy of education. New York: The Free Press. (Original work published 1916)

Dewey, J. (2001). The school and society \& the child and the curriculum. Mineola, NY: Dover Publications, Inc. (Original work published in 1915)

Epstein, T. (2000). Adolescent perspectives on racial diversity in U.S. history: Case studies from an urban classroom. American Educational Research Journal, 37(1), 185-214.

Erickson, F. \& Shultz, J. (1992). Students' experience of the curriculum. In P. Jackson (Ed.), Handbook for research on curriculum (pp. 465-485). New York: MacMillan Publishing Co.

Grumet, M.R. (1988). Bitter milk: Women and teaching. Amherst, MA: The University of Massachusetts Press.

Hogan, D. (1990). Modes of discipline: Affective individualism and pedagogical reform in New England, 1820-1850. American Journal of Education, 99(1), 1-56.

Jackson, P.W. (1990). Life in classrooms. New York: Teachers College Press. (Original work published in 1968)

Judge, H. (1995). The images of teachers. Oxford Review of Education, 21(3), 253-265.

Mosborg, S. (2002). Speaking of history: How adolescents use their knowledge of history in reading the daily news. Cognition and Instruction, 20(3), 323-358. 
Noddings, N. (1992). The challenge to care in schools: An alternative approach to education. New York: Teachers College Press.

Obama, B. (2004). Dreams from my father: A story of race and inheritance. New York: Three Rivers Press.

Rosenzweig, R. \& Thelen, D. (1998). The presence of the past: Popular uses of history in American life. New York: Columbia University Press.

Seixas, P. (1993). Historical understanding among adolescents in a multicultural setting. Curriculum Inquiry, 23, 301-327.

Seixas, P. \& Clark, P. (2004). Murals as monuments: Students' ideas about depictions of civilization in British Columbia. American Journal of Education, 110, 146-171.

Serwer, A. (2009, December 7). The '00s: Goodbye (at last) to the decade from hell. Time. Retrieved December 30, 2009 from: http://www.time.com/time/nation/article/0,8599,1942834,00.html.

Tyack, D. \& Tobin, W. (1994). The "grammar" of schooling: Why has it been so hard to change? American Educational Research Journal, 31(3), 453-479.

Van Manen, M. (2001). Researching lived experience. Cobourg, Ontario: Transcontinental Printing Inc.

Van Manen, M. (1991). The tact of teaching: The meaning of pedagogical thoughtfulness. Albany, NY: State University of New York Press.

Weber, S. \& Mitchell, C. (1995). That's funny, you don't look like a teacher! Interrogating images and identity in popular culture. London: The Falmer Press.

Wertsch, J.V. (2002). Voices of collective remembering. Cambridge, UK: Cambridge University Press.

Wertsch, J.V. \& O’Connor, K. (1994). Multivoicedness in historical representation: American college students' accounts of the origins of the United States. Journal of Narrative and Life History, 4(4), 295-309.

Wineburg, S.S. (2001). Historical thinking and other unnatural acts: Charting the future of teaching the past. Philadelphia: Temple University Press.

\section{Acknowledgement}

The authors wish to express their gratitude to the two anonymous reviewers of this paper - for 
their generosity, insight and detailed suggestions for ways in which to improve the piece. 